
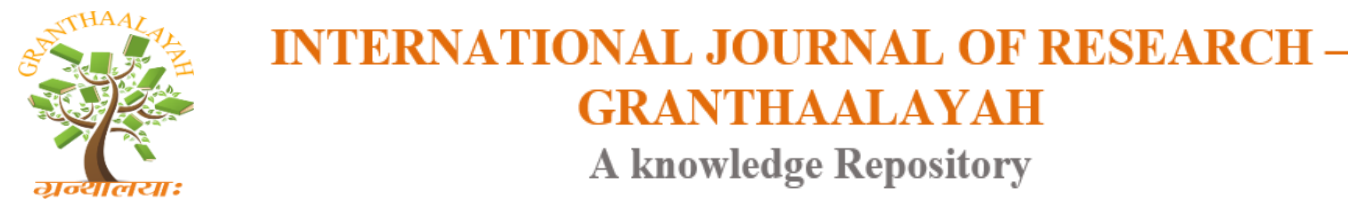

Social

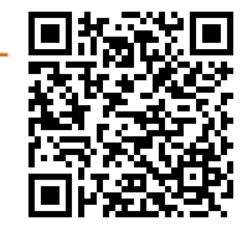

\title{
USE OF WHATSAPP FOR ENGLISH LANGUAGE PROFICIENCY AMONG B.ED. TRAINEES
}

\author{
Dr.N.Ramakrishnan *1 \\ ${ }^{* 1}$ Professor and Head Department of Educational Technology, Tamil Nadu Teachers Education \\ University, Chennai- 600 097, India
}

\begin{abstract}
Whatsapp has attracted over 1.2.billion people worldwide. It uses the Internet to make voice calls, one to one video calls; send text messages, images, GIF, videos, documents, user location, audio files, phone contacts and voice notes to other users using standard cellular mobile numbers. Its use in the administrative side is also on the increase. Recently IAS officers and CEOs have created Whatsapp groups to pass on messages. It is in vogue now. It has many conveniences of sending JPEG, PDF files, photos, videos and audio. There are many apps which are competing with Whatsapp but Whatsapp has emerged as number one among them. The study here is to know the use of Whatsapp for language learning. Overall perception is that the use of English language in the Whatsapp and other social media is on the increase. Immediately it has struck all of us one question that is does it increase the language proficiency of students and others? If so, what would be the effect on the learning of foreign language? It is doing a yeoman service to the students to develop competency in foreign language. English is the most common and widely used language. It is a library and laboratory language too. Development of English language proficiency among B.Ed. trainees is very crucial as it leads to better transaction in the classroom. The marketing of their professional degree is also possible with sound knowledge in English. So, it is the natural quest of the researcher here is to study the use of Whatsapp for Development of English Language Proficiency among B.Ed. trainees. The study was conducted among 200 B.Ed. trainees in Madurai district. It is proved from the above table that the B.Ed. students are using whatsapp more for development of English Language proficiency than expected.
\end{abstract}

Keywords: Whatsapp; B.Ed. Trainees; English Language Proficiency; Use.

Cite This Article: Dr.N.Ramakrishnan. (2017). "USE OF WHATSAPP FOR ENGLISH LANGUAGE PROFICIENCY AMONG B.ED. TRAINEES” International Journal of Research Granthaalayah, 5(9:SE), 1-6. 10.29121/granthaalayah.v5.i9(SE).2017.2245.

\section{Introduction}

WhatsApp Messenger is a freeware, cross-platform and end-to-end encrypted instant messaging application for smart phones. It uses the Internet to make voice calls, one to one video calls; send 
text messages, images, GIF, videos, documents, user location, audio files, phone contacts and voice notes to other users using standard cellular mobile numbers. It also incorporates a feature called Status, which allows users to upload photos and videos to a 24-hours-lifetime feed that, by default, are visible to all contacts; similar to Snapchat, Facebook and Instagram Stories. Whatsapp has attracted over 1.2.billion people worldwide. It uses the Internet to make voice calls, one to one video calls; send text messages, images, GIF, videos, documents, user location, audio files, phone contacts and voice notes to other users using standard cellular mobile numbers.It's use in the administrative side is also on the increase. Recently IAS officers and CEOs have created Whatsapp groups to pass on messages. It is in vogue now. It has many conveniences of sending JPEG, PDF files, photos, videos and audio. There are many apps which are competing with Whatsapp but Whatsapp has emerged as number one among them. The study here is to know the use of Whatsapp for language learning. Overall perception is that the use of English language in the Whatsapp and other social media is on the increase. Immediately it has struck all of us one question that is does it increase the language proficiency of students and others? If so, what would be the effect on the learning of foreign language? It is doing a yeoman service to the students to develop competency in foreign language. English is the most common and widely used language. It is a library and laboratory language too. Development of English language proficiency among B.Ed. trainees is very crucial as it leads to better transaction in the classroom. The marketing of their professional degree is also possible with sound knowledge in English. So, It is the natural quest of the researcher here is to study the use of Whatsapp for Development of English Language Proficiency among B.Ed. trainees.

\section{Terms and Definitions}

- Use - refers to apply

- Whatsapp - refers to uses the Internet to make voice calls, one to one video calls; send text messages, images, GIF, videos, documents, user location, audio files, phone contacts and voice notes to other users using standard cellular mobile numbers.

- English Language - Language of British People

- Proficiency - refers to expertise

- B.Ed. Trainees - refers to those who are studying Bachelor of Education Course in the first and second year of two year B.Ed. programme.

\section{Objectives of the Study}

The study has formulated the following objectives,

1) To find out the use of whatsapp for development of English Language proficiency among B.Ed. trainees.

2) To find out significant difference in the use of whatsapp for development of English language proficiency among B.Ed. students in terms of Gender.

3) To find out significant difference in the use of whatsapp for development of English language proficiency among B.Ed. students in terms of qualification.

\section{Hypotheses Formulated for the Study}

The hypotheses have been stated in null form: 
1) The use of whatsapp for development of English Language proficiency among B.Ed. trainees is average.

2) There is no significant difference in the use of whatsapp for development of English language proficiency among B.Ed. students in terms of Gender.

3) There is no significant difference in the use of whatsapp for development of English language proficiency among B.Ed. students in terms of qualification.

\section{Instrumentation}

The researcher prepared a rating scale with 50 items on Use of Whatsapp for development of language proficiency among B.Ed. trainees after item analysis only 38 items were selected for the final form of the use of Whatsapp for development of language proficiency among B.Ed. trainees. The ratings were Strongly Agree, Agree, Undecided, Disagree and Strongly Disagree.

\section{Establishment Reliability of the Tool}

\subsection{Test and Retest Method}

The questionnaire was administrated among the 40 B.Ed. trainees and re administrated among the same 40 trainees after a gap of 15 days. The correlation found between the two administrations was 0.81 . Thus the reliability of the questionnaire was ensured.

\subsection{Establishing Validity of the Tool}

The investigator has consulted experts for the preliminary form of the use of Whatsapp for development of language proficiency among B.Ed. trainees. The consultation had with subject experts ensures face and content validity of the questionnaire. According, to Garret, H.E (1967, $\mathrm{P}, 365)$ the index of reliability is sometimes taken as a measure of validity.

\subsection{Scoring}

For the purpose of scoring, the ratings strongly Agree, Agree, Undecided, Disagree and Strongly Disagree were given marks as 5,4,3,2 and 1. The maximum mark in the questionnaire would be 190. The total marks secured by each trainee were used for average.

\section{Sample Design}

The investigator has followed stratified random sampling method for the present study. The strata were Government Aided and Self- financing B.Ed. Colleges in Madurai District. The investigator has collected a sample of 200 trainees.

The details regarding null hypotheses stated and decisions regarding the hypotheses are presented in the following paragraphs.

Hypothesis 1: The use of whatsapp for development of English Language proficiency among B.Ed. trainees is average. 
Table 1: Descriptive Analysis for the Use of Whatsapp for Development of English Language Proficiency among B.Ed. Trainees.

\begin{tabular}{|l|l|l|}
\hline S.No & Description & Value \\
\hline 1. & Mean & 143.98 \\
\hline 2. & Standard Deviation & 20.63 \\
\hline 3. & Low Score & 11 \\
\hline 4. & Highest Score & 183 \\
\hline 5. & Mode & 141 \\
\hline 6. & Median & 146 \\
\hline 7. & Theoretical Mean & 95 \\
\hline
\end{tabular}

It is evident from Table 4.1 that the median and mode values for the B.Ed. trainees on use of whatsapp for development of English Language proficiency are 146 and 141 respectively. The highest score is 183 and the lowest score is 11 . The mean value obtained is 143.98 with standard deviation of 20.63. It is well above the theoretical mean of 95. It is proved from the above table that the B.Ed. students are using whatsapp more for development of English Language proficiency than expected.

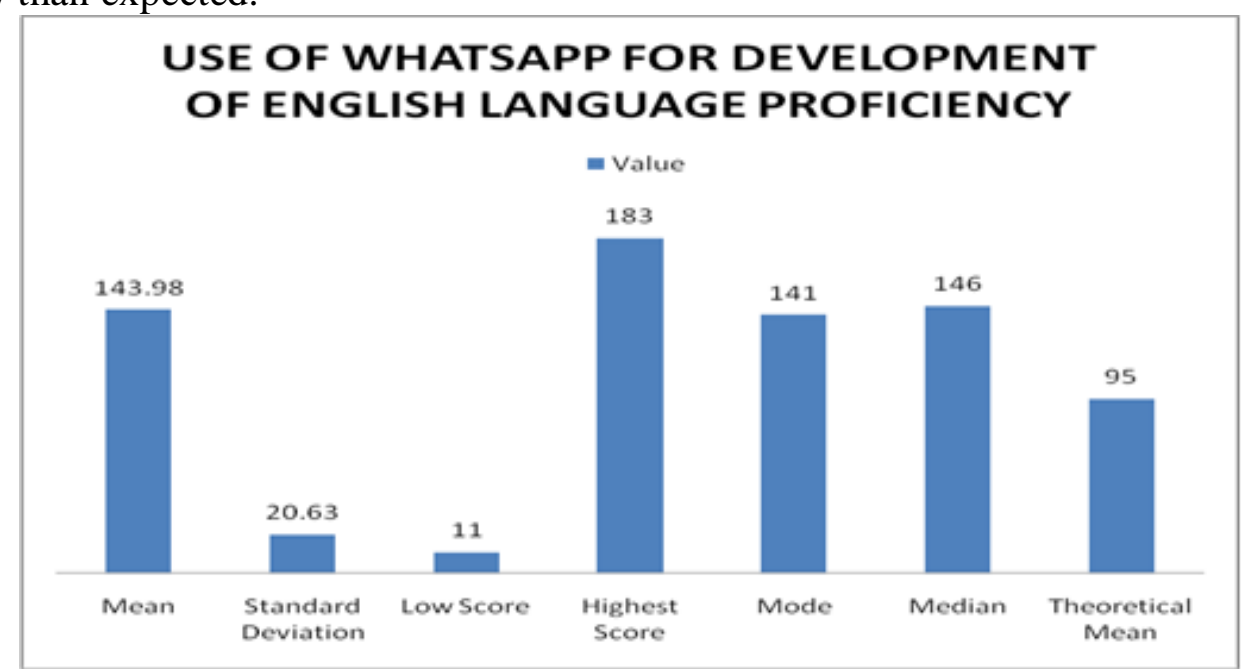

Figure 1: Bar Diagram Showing The Descriptive Analysis Of The Use Of Whatsapp For Development Of English Language Proficiency Among B.Ed. Trainees.

Hypothesis 2: There is no significant difference in the use of whatsapp for development of English language proficiency among B.Ed. students in terms of Gender.

Table 2: Mean, S.D. And 'T' Value for Use of Whatsapp for English Language Proficiency among B.Ed. Students In Terms of Gender

\begin{tabular}{|l|l|l|l|l|l|l|}
\hline Gender & \multicolumn{1}{|c|}{$\mathbf{N}$} & Mean & \multicolumn{1}{|c|}{ S.D } & \multicolumn{1}{|c|}{ 't' } & \multicolumn{1}{c|}{ Critical Value } & $\begin{array}{c}\text { Level of } \\
\text { Significance }\end{array}$ \\
\hline Male & 33 & 148.57 & 18.60 & \multirow{2}{*}{1.401} & $\begin{array}{l}1.960 \text { for df of } 198 \\
\text { at } 0.05 \text { level }\end{array}$ & No Significant \\
\hline Female & 167 & 143.07 & 20.94 & & \\
\hline
\end{tabular}

It is evident from Table 4.2 that the obtained ' $t$ ' value is 1.401 . It is lesser than the critical value of 1.960 for df of 198 at 0.05 level. It is not significant. Hence the hypothesis stated is accepted. 
There is no significant difference in use of whatsapp for development of English language proficiency among B.Ed. students in terms of Gender.

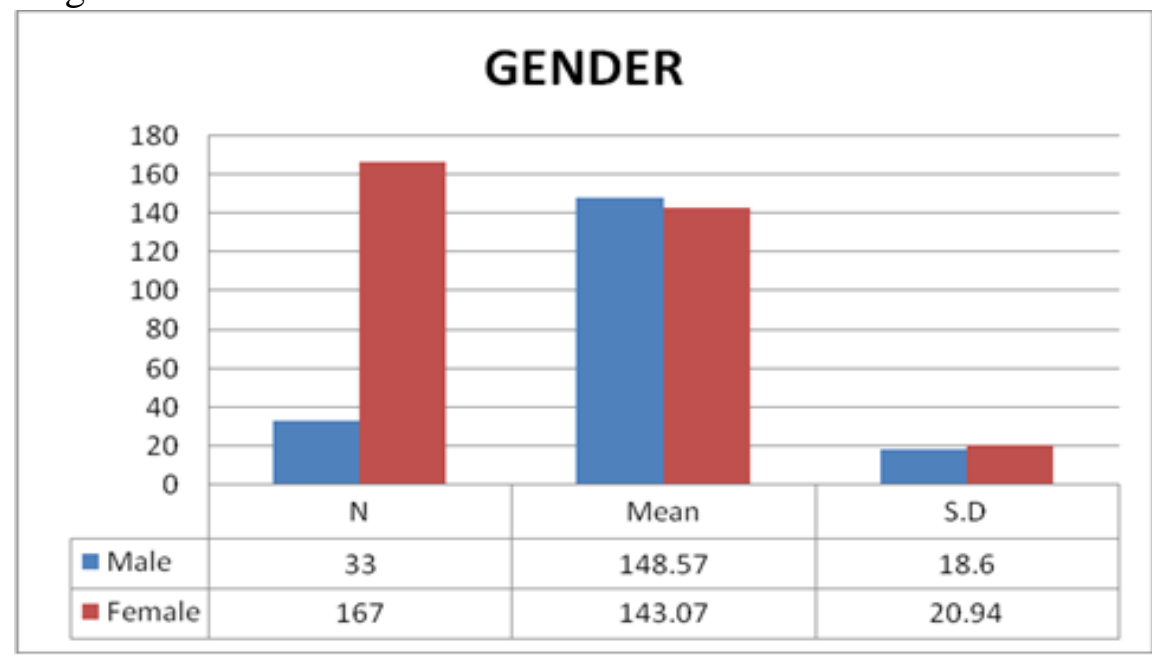

Figure 2: Bar Diagram Showing The Significant Difference In Use Of Whatsapp For Development Of English Language Proficiency Among B.Ed. Students In Terms Of Gender.

Hypothesis 3: There is no significant difference in the use of whatsapp for development of English language proficiency among B.Ed. students in terms of qualification.

Table 3: Mean, S.D. And 'T' Value For Use of Whatsapp for English Language Proficiency among B.Ed. Students In Terms Of Qualification

\begin{tabular}{|l|c|c|c|c|c|c|}
\hline Qualification & N & Mean & \multicolumn{1}{|c|}{ S.D } & ' $\mathbf{t}$ ' & \multicolumn{1}{c|}{ Critical Value } & $\begin{array}{c}\text { Level of } \\
\text { Significance }\end{array}$ \\
\hline UG & 186 & 143.39 & 20.72 & \multirow{2}{*}{1.484} & $\begin{array}{l}1.960 \text { for df of } \\
198 \text { at } 0.05 \text { level }\end{array}$ & No Significant \\
\hline PG & 14 & 151.85 & 18.37 & & \\
\hline
\end{tabular}

It is evident from Table 3 that the obtained ' $t$ ' value is 1.484. It is lesser than the critical value of 1.960 for $\mathrm{df}$ of 198 at 0.05 level. It is not significant. Hence the hypothesis stated is accepted. There is no significant difference in use of whatsapp for development of English language proficiency among B.Ed. students in terms of qualification.

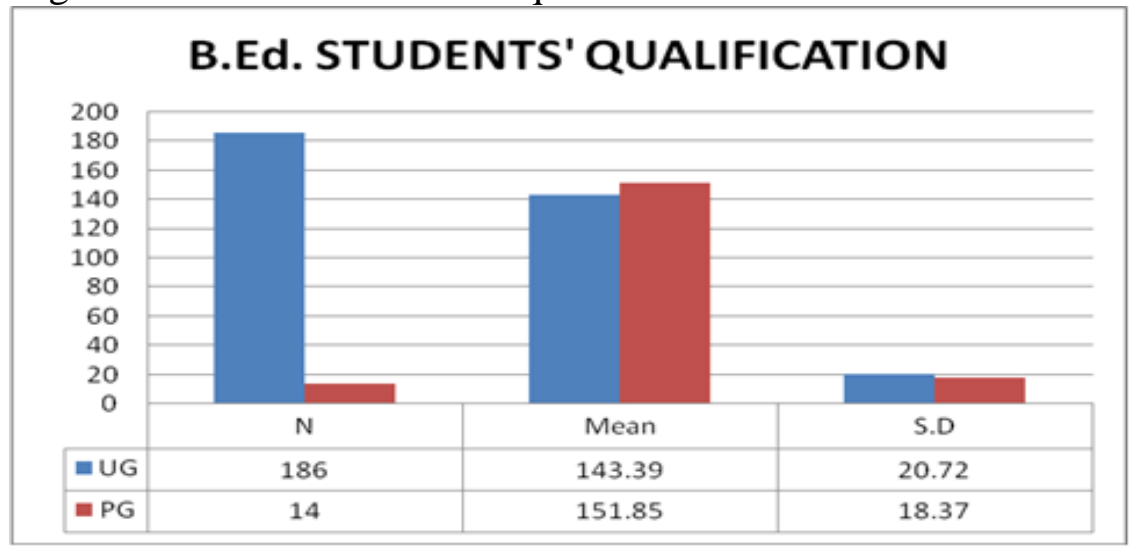

Figure 3: Bar Diagram Showing The Significant Difference In Use Of Whatsapp For Development Of English Language Proficiency Among B.Ed. Students In Terms Of Qualification. 


\section{Conclusion}

The study can be concluded by stating the following. They are:

1) The median and mode values for the B.Ed. trainees on use of whatsapp for development of English Language proficiency are 146 and 141 respectively. The highest score is 183 and the lowest score is 11 . The mean value obtained is 143.98 with standard deviation of 20.63. It is well above the theoretical mean of 95. It is proved from the above table that the B.Ed. students are using whatsapp more for development of English Language proficiency than expected.

2) There is no significant difference in use of whatsapp for development of English language proficiency among B.Ed. students in terms of Gender.

3) There is no significant difference in use of whatsapp for development of English language proficiency among B.Ed. students in terms of qualification.

\section{Educational Implications}

The study has come out with interesting finding that Whatsapp is being used by B.Ed. trainees for English language proficiency. It is natural that everybody is using Whatsapp now for sharing audio, video, text, images and GIF. It has made people learn English language automatically. Very rare people are having Tamil Keyboard in their smart phones. Most of them are using English keyboard only. Common words and sentences have been used more frequently. It naturally enhances English Language proficiency.

\section{References}

[1] Ainsley O'Connell. "Inside Erlang, the Rare Programming Language behind WhatsApp's Success". Fastcolabs.com. Retrieved February 21, 2014.

[2] Albergotti, Reed; MacMillan, Douglas; Rusli, Evelyn M. (February 20, 2014). "Facebook's \$18 Billion Deal Sets High Bar". The Wall Street Journal. pp. A1, A6.

[3] Amit Chowdhry, "WhatsApp Hits 500 Million Users", Forbes, retrieved May 14, 2014

[4] Ash (April 9, 2015). "[Application] NEW Native WhatsApp clients hits the Tizen Store, Goodbye ACL WhatsApp Messenger". Tizen Experts.

[5] Bolton, Doug (24 May 2016). "WhatsApp Gold: Scammers trick mobile phone users into downloading malware". The Independent. Independent Print Limited. Retrieved 8 August 2016.

[6] Bradshaw, Tim (November 14, 2011). "WhatsApp users get the message". The Financial Times. London. Retrieved January 29, 2013.

[7] Golden, S. A. R. (2011). Problems and Prospectus of Distance Education. Quality Enhancement in Distance Education for Life Long Learning, 1(1), 343-344.

[8] Golden, S. A. R. (2016). Rural Students'attitude towards English as Medium of Instruction in Higher Education-An Analysis. International Journal of Research, 3, 1-10.

[9] Golden, S. A. R. (2017). Attitude of Students and Teachers towards E-Learning-An Analysis. Recent Research in Social Science \& Humanities, 1, 5-10.

[10] Golden, S. A. R. (2017). Recent Research in Social Sciences \& Humanities. EduPedia Publications (P) Ltd.

[11] Regi, S. B., \& Golden, S. A. R. (2014). A Study on Educational Loan Availed By Students in Trichy City. Journal of International Academic Research for Multidisciplinary (Jiarm), 2 (1). 